\title{
Perception and use of informal coercion in outpatient treatment: a focus group study with mental health professionals of Latin culture
}

\author{
Ignacio García-Cabeza, ${ }^{1}$ Emanuel Valenti, ${ }^{2}$ Alfredo Calcedo1
}

\author{
1 Servicio de Psiquiatría B, Hos- \\ pital General Universitario Gre- \\ gorio Marañón. Universidad \\ Complutense de Madrid, Madrid, \\ España. \\ 2 Universidad Europea de Madrid, \\ Madrid, España. \\ Correspondence: \\ Ignacio García-Cabeza \\ Servicio B de Psiquiatría. HGU \\ Gregorio Marañón, C/lbiza 43 \\ 28009-Madrid, España. \\ Phone: 0034915868147 \\ E-mail: igcabeza@salud.madrid.org
}

Received first version: June 27 , 2016; second version: September 15, 2016; accepted: February 15, 2017.

https://doi.org/10.17711/ SM.0185-3325.2017.009

\begin{abstract}
Introduction. In addition to compulsion (involuntary hospitalization, seclusion, restraint, etc.), there are broader forms of coercion (persuasion, interpersonal pressure, inducement or threat), called informal or covert coercion, all of which try to improve patients adherence to treatment. Objective. To analyse the use of covert coercion in mental health outpatients and the mental health professionals' views on this practice comparing four countries (Spain, Italy, Mexico and Chile). Methods. We conducted a qualitative research using four focus groups in each country with mental health professionals working in mental health centres and based on a thematic analysis approach. Sample. The total sample was made up of 98 professionals (31 psychiatrists, 25 clinical psychologists, 28 nurses, eight social workers and six other professionals). Results. The use of informal coercion was recognized in clinical practice, but its intensity was related to professionals' characteristics and to factors related to diagnosis, clinical course, perceived risk, insight, therapeutic relationship and organizational issues in the delivery of services. Its use was justified by effectiveness in improving adherence and, generally, in seeking benefits for the patient, but sometimes in a paternalistic way. Discussion and conclusion. Our results match those described in the literature in terms of: 1. sociodemographic and clinical profile; 2. the reason that leads to its use (adherence); 3. ethical justification (search for patient's benefit, trying not to impair his freedom); hence, the most intense forms (threat) were misperceived. Our professionals acknowledged the use of covert coercion in their clinical practice, justifying it on ethical and clinical grounds.
\end{abstract}

Keywords: Coercion, pressure, autonomy, focus group, community mental health services.

\section{RESUMEN}

Introducción. Además de la coerción formal (hospitalización involuntaria, contención, etc.), en salud mental existen otras formas de coerción (persuasión, presión interpersonal, inducción o amenaza), denominada informal o encubierta, que pretenden mejorar la adherencia. Objetivo. Conocer el uso de la coerción informal en el tratamiento ambulatorio de enfermos mentales y la percepción que de ella tienen los profesionales de salud mental de cuatro países (España, Italia, México y Chile). Método. Utilizamos una investigación cualitativa con cuatro grupos focales por país, compuestos por profesionales que trabajaban en centros de salud mental, con un enfoque basado en el análisis temático. La muestra fue de 98 profesionales (31 psiquiatras, 25 psicólogos clínicos, 28 enfermeros, ocho trabajadores sociales y otras seis profesiones). Resultados. Se reconoció el uso de la coerción informal en la práctica clínica. Su intensidad dependió de características del profesional y factores relacionados con el diagnóstico, clínica, evolución de la enfermedad, peligrosidad del paciente, conciencia de enfermedad, relación terapéutica y aspectos organizativos asistenciales. Su uso se justificó por la eficacia y la búsqueda de beneficios para el paciente, a veces de forma paternalista. Discusión y conclusión. Nuestros resultados coincidieron en cuanto al perfil sociodemográfico y clínico con lo descrito en la bibliografía. También lo hicieron en cuanto al motivo que lleva a su uso (la adherencia) y su justificación ética (la búsqueda del beneficio del paciente menoscabando su libertad lo menos posible), de ahí que las formas más intensas (amenaza) fueron mal percibidas. Nuestros profesionales reconocieron el ejercicio de la coerción encubierta en su práctica habitual, justificándola clínica y éticamente.

Palabras clave: Coerción, presión, autonomía, grupo focal, servicios de salud mental. 


\section{INTRODUCTION}

The use of coercive procedures is as frequent in mental health as the debate that generates its use. On the one hand, we find the defense and respect for the rights of the patient; on the other, the need to receive treatment, not always voluntary, that avoids clinical worsening or prevents self-injuries or harm to others (Appelbaum, 2006; EUNOMIA, 2005). When these are regulated, we refer to them as formal coercion (hospitalization, involuntary treatment, reclusion, chemical and mechanical restraint) (Flores, 2003; Jaeger \& Rossler, 2010; Molodynski, Rugkåsa \& Burns, 2010; Monahan et al., 2015).

However, the lack of efficacy in hospital treatment, its restrictions, the transfer of treatment to a community level, and the difficulties of adherence have lead to the use of other coercive strategies, beyond any legislation or regulated procedure. These are known as informal or covert coercion (Molodynski, Rugkåsa \& Burns, 2010; Sjöstrand \& Helgesson, 2008). The most cited classification of this type of coercion was developed by Szmukler and Appelbaum, who, hierarchically, ordered it according to its intensity in: persuasion (giving information and answers to a patient's questions and concerns about his/her treatment); interpersonal leverage (use of the interpersonal relationship to try to influence the decision making), inducement (suggesting the implementation of support or additional services if involved in the suggested treatment) and threat (warning of withdrawal of these supports/services, or mentioning the possibility of formal coercion use) (Szmukler \& Appelbaum, 2008). We used these categories in our study. There are other forms of informal coercion, less investigated but commonly used; for example, deceit (Szmukler \& Appelbaum, 2008).

Research on formal coercion started in the 70's and even. In the European Union, the EUNOMIA project was an attempt to understand the reality of the different situations that characterize mental health in Europe. Based on the EUNOMIA results, guidelines were given to regulate the use of these procedures (Kallert et al., 2005). In the case of covert coercion, research appeared mainly in the last decade, focused on knowing patients' perceptions, especially in Anglo-Saxon and other developed countries (Molodynski, Turnpenny, Rugkåsa, Burns \& Moussaoui, 2014), and with few studies on the opinions of professionals (Appelbaum \& Le Melle, 2008; Claassen, Fakhoury, Ford \& Priebe, 2007; Priebe et al., 2010; Rugkåsa, Canvin, Sinclair, Sulman \& Burns, 2014; Valenti et al., 2015).

In general, the use of informal coercive strategies, for example with financial incentives, has shown effectiveness in improving patients' adherence (Burton, Marougka \& Priebe, 2010; Priebe et al., 2013); justifying their use because they improve health either with a better balance between health and capacity to decide (Szmuk- ler, 2015) or from a paternalistic view (Gert, Culver \& Clouser, 2006). However, there are studies that question their efficacy due to the deterioration that may occur in the therapeutic relationship (Angell, Martinez, Mahoney $\&$ Corrigan, 2007).

The aim of this study was to explore attitudes and experiences of mental health professionals from four countries (Spain, Italy, Mexico and Chile), all of Latin culture, on the use of informal or covert coercion strategies in the treatment of mental health outpatients.

\section{METHOD}

This study was a part of a larger one carried out in 10 countries, grouped into five culturally different regions: Anglo-Saxon, Central European, Scandinavian, Latin and Mediterranean (Valenti et al., 2015). The lack of references on the phenomenon of informal coercion in mental health in countries outside the Anglo-Saxon ones, and the common patterns of providing mental health services among Latin culture countries, led us to make a secondary reading of the data available in Spain, Italy, Mexico and Chile. It also allowed the researchers to analyze the results in the native language of the participants, avoiding possible misinterpretations derived from translations.

\section{Type of study}

The present qualitative study was carried out using focus groups and thematic analysis of the contents (Braun \& Clarke, 2006). This type of analysis allowed us to identify common patterns of data, which are essential to understand the investigated phenomenon.

Four focus groups were conducted per country, with between four to eight professionals per group, sufficient to achieve intra and intergroup saturation (Onwuegbuzie, Dickinson, Leech \& Zoran, 2009).

\section{Research team's characteristics}

Emanuele Valenti (EV) is a professor of bioethics at the Biomedical Sciences Faculty at the European University of Madrid and expert in qualitative methodology. He coordinated both the original study and its data analysis (Valenti et al., 2015) as this present secondary study. He conducted the focus groups in the four countries studied, with a passive-observer role and participated directly in the codification.

Doctor Ignacio García Cabeza (IGC) is a psychiatrist at the Gregorio Marañón University Hospital, participated in the validation process of the coding and, together with EV, in the analysis of the data from the four countries.

Professor Alfredo Calcedo (Complutense University of Madrid) is an expert psychiatrist in Legal Psychiatry and 
has collaborated with the other authors in the organization of the study and the diffusion of results.

\section{Participants}

An intentional sampling was performed to obtain greater representativeness of professionals involved in the treatment of these patients: presence of both genders, of all significant professions and diversity at the time of experience.

The inclusion criteria in the focus groups were:

- Less than 65 years old.

- Qualified as a psychiatrist, psychologist, nurse, social worker or therapist.

- At least one year of experience in a Mental Health Center after having finished professional training.

- Working with outpatients with severe mental disorders on whom some form of coercion has been applied.

\section{Gathering of information}

Four focal groups per country were performed, digitally recorded, and subsequently transcribed. One of the Chilean focus groups was discarded because of the poor quality of the recording.

Each group lasted between 60 and 120 minutes. After a brief description of the project, and a presentation of the participants, a general discussion was carried out where each participant's understanding of the main topic was explored (define the general concepts related to the contents of the research, ask if they knew the difference between formal and informal coercion). The different categories of coercion were then defined according to Smuzkler and Appelbaum (2008), which were exemplified by one or two cases adapted from Molodynski (2010). Group members were asked if they were aware of other types of informal coercion, and if it was possible to establish a continuum between all these types of influences or pressures.

After the presentation and discussion of the cases, a second general discussion was held to explore the attitudes of professionals and their views on the possibility of establishing a correspondence between a patient's particularities and possible types of coercion. They were asked about the impact of coercion on patient satisfaction and adherence, and on the patient's typology on whom informal coercion was applied; as well as whether each type of patient would correspond with a type of coercion.

Finally, we concluded with a summary of the discussion and stimulating different perspectives and opinions.

Throughout the process, the moderator explored participants' attitudes and experiences using standardized probing questions, using Socratic questioning (inquiring about the meaning of emerging contents), and asking for clarification and inviting for more details.
Transcriptions were analyzed with the QSR N-Vivo qualitative software package.

\section{Procedures}

Mental Health Centers, where treated patients may need involuntary treatments, were identified. The study was presented by letter to the head of the center and, if they agreed to participate, each service presented a list of professionals who met inclusion criteria. Participants were selected in relation to the inclusion criteria established in the study and signed an informed consent.

The groups were held in the workplace in a quiet room suitable for recording the sessions. All sessions took place between January 2013 and April 2014.

\section{Analysis of the information}

The coding was done with material from the 10 countries that participated in the matrix study. Initially, two researchers, including EV, independently performed the coding, line by line, of 16 transcripts to generate the initial categories. In order to evaluate their reliability, eight researchers (including IGC) used this preliminary framework to code eight different transcriptions, obtaining agreement rates ranging from $80 \%$ to $98.5 \%$.

Thematic analysis was carried out using an iterative process (Braun \& Clarke, 2006). The different categories were compared and linked to different topics, selected through regular discussion with the research team. After identifying the topics, the research team re-read each transcription to ensure that they were firmly based on the data, to refine topics, and to locate illustrative citations.

\section{Ethical consideration}

The study met all the ethical requirements for its realization. All participants signed the informed consent individually, and after receiving written information about the purpose and procedure of the study. All selected professionals agreed to participate.

The analysis of the texts was done respecting the anonymity of the group members at all times, encrypting the focal group (1-4), and assigning an order number to each participant (01-30). The countries of origin of the group were represented by: SP (Spain); IT (Italy); MX (Mexico); $\mathrm{CH}$ (Chile).

In Spain the project was approved by the ethics committee of the Alcorcón Foundation Hospital (Madrid) and in Chile by the General Director of the University Clinical Hospital. Italy and Mexico did not require approvals by local ethical committees, once the overall project was approved. 


\section{RESULTS}

A total of 98 professionals participated: 30 Spaniards (10 psychiatrists, five clinical psychologists, 10 nurses, four social workers and one occupational therapist), 23 Italians (10 psychiatrists, 12 nurses and one social worker), 24 Mexicans (three psychiatrists, 15 psychologists, two nurses and four other professions), and 21 Chileans (eight psychiatrists, five psychologists, four nurses, three social workers and one therapist).

Three main themes were found: (a) concept of coercion, (b) process in decision making, and (c) perception of participants.

\section{A. Concept of coercion}

The concept of coercion implies trying to influence or pressure a patient in different ways to achieve our goals. All participants in the focus groups described what they are referring to and how to act when exercising any kind of pressure on the patient, distinguishing formal from informal or covert coercion.

"... for me coercion is to induce a person to do something against his will. If I do, I act on their motivations, their values, and on what is important for that person, we influence them ..." (FGIT425)

“... is to force or induce someone to do something that does not want through an affective element that is exploited" (FGMX208)

\section{B. Process in decision making}

When analyzing the decision making process, we found two different categories: who makes the decision and what factors lead to making it.

\section{B.1. Who makes the decision}

When we analyze who was responsible for the decision making on the use and type of coercion, it was evident in all countries that it depended on the professionals: their characteristics, abilities, personality and even nonconscious elements, which marked the intervention and its intensity.

"... I have information and I know that with this information from this patient I can use certain things, not others, because they are going to be counterproductive, my skills are those that allow me to handle the patient ..." (FGSP424)

"... it has to be handled very carefully, the therapist should be aware of all those issues that could influence the treatment of his patients, and that he did not overreact in the management, I say, of the involuntary treatment, or the threat when the patient does not require it, but maybe he should consider it as a way to discharge his own unconscious hostility, OK? ..." (FGMX213)
It was also true that professionals preferred that this decision was valued and taken in a multidisciplinary team, which would allow not only for sharing and reaching consensus, but also in a team appeared different roles to seek the best option for the patient:

"... teamwork is fundamental, that is, ... I speak as a nurse, from the perspective of the multidisciplinary team: the nursing staff uses everything from persuasion, influence, induction, threat, coercion, and prior to formal coercion ... but always from a multidisciplinary point of view, ..." (FGSP207)

"... support in a multidisciplinary team is a way, I understand, a bit of sharing responsibilities but also to protect the clinical relationship and the alliance with the patient and the responsibility for exercising authority is not borne solely as threatening the patient" (FCH108)

\section{B.2. Influential factors in decision making}

The factors that the participants considered most important when choosing the type and intensity of the coercive procedure were related to the disease (diagnosis, clinical and outcome), the patient (danger and insight), the therapeutic relationship, adherence and organizational aspects of care.

Regarding the clinical aspects, we did not find a specific diagnosis but the presence of a severe mental disorder (tending to the chronicity and disability according to the ICD-10 criteria), together with the clinical intensity, severity and chronicity of the disease, determined the type and intensity of the coercive strategy:

“... we are talking about severe mental disorder, such as..., well this is not that other [patients] are not serious, that too... I believe where all these things are given is in alcoholics, people who are consuming [drugs] ..." (FGSP105)

"Personally I think it is based mainly on the diagnosis, but above all, on knowing how the patient relapses more than on the diagnosis itself, ..." (FGIT319)

"... the intervention goes in crescendo in parallel to the patient's symptomatology increases" (FGSP428)

The dangerousness of the patient was another key element for intervention, either in the form of harm to others or risk for his own life, being numerous the examples in this regard:

"... of course, the risk, the knowledge of the patient, the knowledge that there is a psychopathological substrate, then if I have the feeling that there is a lack of control, I have to decide and in an interventional and gradually more threatening way..." (FGIT208)

"... you have to explain to the patient that if he does not comply with that treatment he puts himself at risk, puts the family at risk and is going to suffer a deterioration that you have to heal and decide for him ..." (FGSP209)

Also in relation to a patient, insight was key in deciding a coercive intervention: 
"... we would be with the whole group that involves schizophrenics, paranoids, depressives and well, we could add addicts there ... it depends a lot on the patient's awareness ..." (FGMX314)

“... patients have an altered consciousness, they do not even have awareness of what is happening until after ..." (FGCH305)

So far we have outlined aspects related to the patient, his illness and the consequences of it. Therapeutic relationship was also an influential factor:

"... other criteria that come to mind on how to choose one of these strategies ... the relationship you have with the patient" (FGIT324)

"... it does have more to do with the question of both the patient and the therapist, in general, how I relate to his personality or characteristics, rather more than the therapeutic approach ..." (FGMX211)

And in the same vein, the need to achieve a therapeutic objective with these interventions, specifically adherence, its reinforcement and active participation in the treatment:

"... is decompensated, you are almost forced to implement these strategies, a little subtler, if you wish, is the gold standard to force patients to participate in the project, to agree with me ..." (FGIT216)

"... between compensations, then take advantage of it to strengthen adherence to the treatment a little ..." (FGCH304)

Finally, we must refer to organizational aspects of care as elements that generated coercive attitudes on patients:

"This discussion has been possible here because we work in this way. Elsewhere, when they are ill, they go to the emergency room. We do not do domiciliary visits to see patients ... it's a different approach" (FGIT101)

"Apart from the fact that in institutions, there are not enough places with the right facilities, with the right programs. It is also a problem the idea that you have to apply it ..." (FGMX421)

\section{Professionals' perception}

In this section we highlight three main thematic groups: clinical justification, ethics and the dissociation between the use and perception of some coercive strategies:

\section{C.1. Clinical justification}

The clinical justification was based mainly on the fact that the use of coercive procedures improves clinical outcomes, especially achieving a better adherence:

"... to avoid the consequences of your own clinical situation, ..." (FGSP428)

"... it seems to me that the impact of any of these treatments, as you said before, on the patient's well-being and adherence to treatment and that ..." (FGMX213)

\section{C.2. Ethical justification}

Ethical justification derived precisely from that quest for patient benefit, generally attempting to maintain its capacity to decide:

"... I am imposing my point of view, for the sake of the patient, so that then, maybe the guilt of manipulating them. I have, for their own good, to limit their will. In the beginning I am in an exchange of collaboration, understanding ..." (FGIT317)

"... and still has some level of awareness maintained, so as to be able to resort to those memories and those affections ... and how they think and feel that the decision making is theirs ..." (FGCH107)

But on other situations in a clearly paternalistic perspective:

"... the patient is used to seeing the doctor and the type of relationship, perhaps more paternalistic because it gives him security, because he says "he knows what is right for me, he knows it", ... means not free but "I'm always used to it." And choosing "you can do this or that" is more difficult, more anxiety. So the model, in this sense I mean ..." (FGIT214)

"Well, it seems, like a type of Holy Inquisition, as well as that the psychiatrist puts in the role of chasing the madness and almost, almost... finishes with it, beyond the will of the patient ..." (FGMX208)

\section{C.3. Dissociation between perception and use}

Although, as we have seen, there is both a clinical and ethical justification for the use of coercive strategies, it is no less true that the perception, especially of the most intense strategies (induction and threat), was negative and there was a certain resignation regarding the need to use them.

"... I mean, to think that you are doing something for the patient's sake, but I feel, I feel ... like induction, threat and coercive things ..." (FGIT317)

"It is a punishment for not doing the things that we order them, ... in other cases, it is used ..." (FGSP314)

\section{DISCUSSION AND CONCLUSION}

The objective of the study was to know the attitude and experiences of mental health professionals from Spain, Italy, Mexico, and Chile, all of Latin culture, on the use of informal or covert coercion strategies in the outpatient treatment of mental illness.

It was evident that in the countries studied, and in general in the revised scientific literature, there is a wide use of coercive procedures, beyond their unpopularity (Szmukler \& Appelbaum, 2008; Valenti et al., 2015) and, in the case of informal measures, the percentage of patients who report having suffered from it is fairly constant in the studies re- 
viewed, ranging from $44 \%$ to $59 \%$ (Molodynski, Rugkåsa $\&$ Burns, 2010), being 35\% in the most favorable (Burns, 2011).

The weight of the decision on coercion fell on the professional, although its use in assertive community treatment teams has also been studied (Diamond, 1996; Monahan, 2005), being well perceived by patients, in general (Angell, Mahoney \& Martinez, 2006; Appelbaum \& Le Melle, 2008; McGrew, Wilson \& Bond, 2002).

The sociodemographic and clinical profile of the subject on whom covert coercion was applied coincides with that described in the literature and corresponded to patients with psychosis and/or substance use disoders (Angell, Martinez, Mahoney \& Corrigan, 2007; Appelbaum \& Redlich, 2006; Burns, 2011; Monahan et al., 2001), severe and chronic illness (Appelbaum \& Redlich, 2006; Burns et al., 2011; Molodynski, Rugkåsa \& Burns, 2010; Monahan et al., 2005), poor insight (Gert, Culver \& Clouser, 2006; Jaeger \& Rossler, 2010), and dangerousness (Conrad et al., 2006; Monahan et al., 2001).

The importance of our study lies in its clinical and ethical implications. For the former, coercive strategies, according to our professionals, improved adherence to treatment and resources, and reduced the need for more intense forms of coercion (Canvin, Rugkåsa, Sinclair \& Burns, 2013; Monahan, 2001). There are authors who even suggest including them within a quality treatment in a patient-centered approach, extending it so that any intervention would be experienced by the patient as a therapeutic care relationship (Bonnie \& Monahan, 2005).

Our professionals agreed when justifying the use of these strategies in their effectiveness and, in fact, several studies, which used economic incentives, found that they improved adherence (Burton, Marougka \& Priebe, 2010; Priebe, 2013); global functioning (Appelbaum \& Redlich, 2006) and quality of life (Angell, Martinez, Mahoney \& Corrigan, 2007). However, there are also authors who consider it negatively because of the possibility of stigma, loss of the therapeutic relationship and pose a barrier in treatment (Angell, Martinez, Mahoney \& Corrigan, 2007; Swartz, Swanson \& Hannon, 2003). More studies are needed to clarify the efficacy of them.

Another added value of our research is the fact that, as far as we know, it is the only study on informal coercion that took place in Mediterranean and Latin-American countries. It is estimated that in these cultures, as well as the Eastern ones, the treatment is more based on cultural attitudes and non-professional patterns of care (Molodynski, Turnpenny, Rugkåsa, Burns \& Moussaoui, 2014; Vázquez-Barquero \& Garcia, 1999), and also, that autonomy is considered in a different way from North-European or Anglo-Saxon cultures. The former place more emphasis than the latter on social integration in the community and dependence (Okasha, 2000). This may justify that in our results we found some paternalism in its use (Gert, Culver \& Clouser, 2006), and that the dissociation between use and perception of the threat is less than in other countries (Valenti et al., 2015).

This brings us directly to the ethical aspects of using coercive strategies. We have previously commented that dangerousness was an element that influenced the use of coercive procedures; however this should mainly refer to the use of formal coercion. Although some actions may be acceptable in order to protect others, medical treatment is justified only in the interest of patients (Sjöstrand \& Helgesson, 2008; Szmukler \& Appelbaum, 2008).

In fact, according to Diego Gracia, we think that the decision to use coercive strategies should be taken within a process of moral deliberation, in which through discussion we opted for a strategy that would achieve the greatest benefit to the patients' health with the least impairment of their freedom (Júdez \& Gracia, 2001). In that sense, some of our results supported making shared and consensual decisions within multidisciplinary teams versus the individual.

As we have already defended in the method section, the choice of a qualitative methodology is a strength of the study, since it explored the professional's perceptions from different countries and with different cultures and health systems. So it was the important number and variety of professionals who participated, 98 professionals in 16 groups, which is not frequent in this type of studies. It may also be a reference study in Mediterranean and Latin American countries where, to the best of our knowledge, no previous research on this topic has been made. The high intergroup saturation suggests that our results were consistent.

The weaknesses of the study were that being a selection of countries within the larger study makes the script of the groups sessions, and subsequent codification of the information was common to the study matrix and not specific to Latin countries.

Among the mental health professionals in the studied countries there was a widespread use of informal or covert coercion, with both ethical and clinical justifications, based mainly on the pursuit of benefit for the patient; although there was also a negative perception in the use of its more intense forms.

\section{Funding}

None.

\section{Conflict of interests}

The authors declare they have no conflict of interests.

\section{REFERENCES}

Angell, B., Mahoney, C. A., \& Martinez, N. I. (2006). Promoting treatment adherence in assertive community treatment. Social Service Review, 80(3), 485-526. https://doi.org/10.1086/505287 
Angell, B., Martinez, N. I., Mahoney, C. A., \& Corrigan, P. W. (2007). Payeeship, financial leverage, and the client-provider relationship. Psychiatric Services, 58(3), 365-372. https://doi.org/10.1176/ps.2007.58.3.365

Appelbaum, P. S. (2006). Law \& Psychiatry: Twenty-Five Years of Law and Psychiatry. Psychiatric Services, 57(1), 18-20. https://doi.org/10.1176/appi.ps.57.1.18

Appelbaum, P. S., \& Le Melle, S. (2008). Techniques used by assertive community treatment $(\mathrm{ACT})$ teams to encourage adherence: patient and staff perceptions. Community mental health journal, 44(6), 459-464. https://doi.org/10.1007/ s10597-008-9149-4

Appelbaum, P. S., \& Redlich, A. (2006). Use of leverage over patients' money to promote adherence to psychiatric treatment. The Journal of nervous and mental disease, 194(4), 294-302. https://doi.org/10.1097/01.nmd.0000207368.14133.0c

Bonnie, R. J., \& Monahan, J. (2005). From coercion to contract: reframing the debate on mandated community treatment for people with mental disorders. Law and Human Behavior, 29(4), 485. https://doi.org/10.1007/s10979-005-5522-9

Braun, V., \& Clarke, V. (2006). Using thematic analysis in psychology. Qualitative research in psychology, 3(2), 77-101. https://doi.org/10.1191/1478088706qp063oa

Burns, T., Yeeles, K., Molodynski, A., Nightingale, H., Vazquez-Montes, M., Sheehan, K., Linsell, L. (2011). Pressures to adhere to treatment ('leverage') in English mental healthcare. The British Journal of Psychiatry, 199(2), 145-150.

Burton, A., Marougka, S., \& Priebe, S. (2010). Do financial incentives increase treatment adherence in people with severe mental illness? A systematic review. Epidemiologia e psichiatria sociale, 19(03), 233-242.

Canvin, K., Rugkåsa, J., Sinclair, J., \& Burns, T. (2013). Leverage and other informal pressures in community psychiatry in England. International journal of law and psychiatry, 36(2), 100-106.

Claassen, D., Fakhoury, W. K., Ford, R., \& Priebe, S. (2007). Money for medication: financial incentives to improve medication adherence in assertive outreach. The Psychiatrist, 31(1), 4-7.

Conrad, K. J., Lutz, G., Matters, M. D., Donner, L., Clark, E., \& Lynch, P. (2006). Randomized trial of psychiatric care with representative payeeship for persons with serious mental illness. Psychiatric Services, 57(2), 197-204.

Diamond, R. J. (1996). Coercion and tenacious treatment in the community. In Dennis, D. L., Monathan, J. (eds.) Coercion and aggressive community treatment (pp. 51-72). USA: Springer US.

EUNOMIA Project. (2005). La utilización de medidas coercitivas en Psiquiatría. Actas Esp Psiquiatr, 33(5), 331-338.

Flores, L. F. B. (2003). Uso de medios coercitivos en Psiquiatría: retrospectiva y propuesta de regulación. DS: Derecho y salud, 11(2), 141-164.

Gert, B., Culver, C. M., \& Clouser, K. D. (2006). Bioethics: a return to fundamentals. 2da. Edición. Oxford University Press. 384 p.

Jaeger, M., \& Rossler, W. (2010). Enhancement of outpatient treatment adherence: Patients' perceptions of coercion, fairness and effectiveness. Psychiatry research, 180(1), 48-53.

Júdez, J., \& Gracia, D. (2001). La deliberación moral: el método de la ética clínica. Medicina clínica, 117(1), 18-23.

Kalla, O., Aaltonen, J., Wahlström, J., Lehtinen, V., García-Cabeza, I. G., González de Chávez, M. (2002). Duration of untreated psychosis and its correlates in first-episode psychosis in Finland and Spain. Acta Psychiatrica Scandinavica, 106(4), 265-275.
Kallert, T. W., Glöckner, M., Onchev, G., Raboch, J., Karastergiou, A., Solomon, Z., ..., Kjellin, L. (2005). The EUNOMIA project on coercion in psychiatry: study design and preliminary data. World Psychiatry, 4(3), 168-172.

McGrew, J. H., Wilson, R. G., \& Bond, G. R. (2002). An exploratory study of what clients like least about assertive community treatment. Psychiatric Services, 53(6), 761-763.

Molodynski, A., Rugkåsa, J., \& Burns, T. (2010). Coercion and compulsion in community mental health care. British medical bulletin, 95(1), 105-119.

Molodynski, A., Turnpenny, L., Rugkåsa, J., Burns, T., \& Moussaoui, D. (2014). Coercion and compulsion in mental healthcare-An international perspective. Asian journal of psychiatry, 8, 2-6.

Monahan, J., Bonnie, R. J., Appelbaum, P. S., Hyde, P. S., Steadman, H. J., \& Swartz, M. S. (2001). Mandated community treatment: Beyond outpatient commitment. Psychiatric Services, 52(9), 1198-1205.

Monahan, J., Redlich, A. D., Swanson, J., Robbins, P. C., Appelbaum, P. S., Petrila, J., ..., McNiel, D. E. (2005). Use of leverage to improve adherence to psychiatric treatment in the community. Psychiatric Services, 56(1), 37-44.

Okasha, A. (2000). Ethics of psychiatry practice: consent, compulsion, and confidentiality. Current Opinion in Psychiatry, 13(6), 693-698.

Onwuegbuzie, A. J., Dickinson, W. B., Leech, N. L., \& Zoran, A. G. (2009). A qualitative framework for collecting and analyzing data in focus group research. International journal of qualitative methods, 8(3), 1-21.

Priebe, S., Sinclair, J., Burton, A., Marougka, S., Larsen, J., Firn, M., Ashcroft, R. (2010). Acceptability of offering financial incentives to achieve medication adherence in patients with severe mental illness: a focus group study. Journal of medical ethics, 36(8), 463-468.

Priebe, S., Yeeles, K., Bremner, S., Lauber, C., Eldridge, S., Ashby, D., ..., Burns, T. (2013). Effectiveness of financial incentives to improve adherence to maintenance treatment with antipsychotics: cluster randomised controlled trial. BMJ, 347, f5847.

Rugkåsa, J., Canvin, K., Sinclair, J., Sulman, A., \& Burns, T. (2014). Trust, deals and authority: community mental health professionals' experiences of influencing reluctant patients. Community mental health journal, 50(8), 886-895.

Sjöstrand, M., \& Helgesson, G. (2008). Coercive treatment and autonomy in psychiatry. Bioethics, 22(2), 113-120.

Szmukler, G. (2015). Compulsion and "coercion" in mental health care. World Psychiatry, 14(3), 259-261.

Szmukler, G., \& Appelbaum, P. S. (2008). Treatment pressures, leverage, coercion, and compulsion in mental health care. Journal of Mental Health, 17(3), 233-244.

Swartz, M. S., Swanson, J. W., \& Hannon, M. J. (2003). Does fear of coercion keep people away from mental health treatment? Evidence from a survey of persons with schizophrenia and mental health professionals. Behavioral sciences \& the law, 21(4), 459-472.

Valenti, E., Banks, C., Calcedo-Barba, A., Bensimon, C. M., Hoffmann, K. M., Pelto-Piri, V., ..., Priebe, S. (2015). Informal coercion in psychiatry: a focus group study of attitudes and experiences of mental health professionals in ten countries. Social psychiatry and psychiatric epidemiology, 50(8), 1297-1308.

Vázquez-Barquero, J. L., \& Garcia, J. (1999). Deinstitutionalization and psychiatric reform in Spain. European archives of psychiatry and clinical neuroscience, 249(3), 128-135. 